\title{
Comparative Effectiveness of Median Sternotomy vs Minimal Access Cardiopulmonary Bypass and Circulatory Arrest for Resection of Renal Cell Carcinoma with Inferior Vena Caval Extension
}

\author{
William C. Faust ${ }^{*}$, Richard S. D'Agostino², John Libertino \\ ${ }^{1}$ Mystic Valley Urology Associates, Stoneham, MA, USA \\ ${ }^{2}$ Lahey Hospital and Medical Center, Burlington, MA, USA \\ Email: ^faustb@gmail.com
}

How to cite this paper: Faust, W.C., D'Agostino, R.S. and Libertino, J. (2016) Comparative Effectiveness of Median Sternotomy vs Minimal Access Cardiopulmonary Bypass and Circulatory Arrest for Resection of Renal Cell Carcinoma with Inferior Vena Caval Extension. Journal of Cancer Therapy, 7, 752-761.

http://dx.doi.org/10.4236/jct.2016.710076

Received: August 27, 2016

Accepted: October 14, 2016

Published: October 17, 2016

Copyright $\odot 2016$ by authors and Scientific Research Publishing Inc. This work is licensed under the Creative Commons Attribution International License (CC BY 4.0).

http://creativecommons.org/licenses/by/4.0/ (c) (i) Open Access

\section{Abstract}

Introduction: The use of cardiopulmonary bypass (CPB) with deep hypothermic circulatory arrest (DHCA) is an adjunctive surgical technique that can be employed for the resection of renal cell carcinoma (RCC) with venous thrombus extension superior to the level of the hepatic veins. Median Sternotomy (MS) or Minimal Access (MA) incisions may be used to establish CPB during the resection of these extensive tumors. We review our experience with both incisional approaches and compareoperative details, perioperative complications, and recurrence free survival. Materials and Methods: From 1986 to 2012, 70 radical nephrectomies with concomitant inferior vena cava (IVC) thrombectomies were performed at our institution using MS (23 patients) and MA (47 patients) techniques. Preoperative patient characteristics, pathologic data, and organ specific postoperative complications and follow-up data were compared between groups. Estimates of overall and recurrence-free survival were constructed using Kaplan-Meier curves and compared using log-rank testing. Results: There were no significant differences with respect to patient demographics or preoperative comorbid conditions between the MA and MS groups. The MA group showed a significant reduction $(\mathrm{p}<0.05)$ in the duration of postoperative mechanical ventilation, length of stay, operative time, and number of blood transfusions compared to MS patients. Overall and organ-system specific complications demonstrated a decreased incidence of wound infection (37.9\% v. $12.5 \%, \mathrm{p}=0.0135$ ) and sepsis $(14.3 \%$ v. $0 \%, \mathrm{p}=0.0137)$ in patients undergoing MA approach. Perioperative mortality was significantly reduced in the MA group $(30.4 \% \mathrm{v} .8 .5 \% \mathrm{p}=$ 0.0179 ). Recurrence-free survival in the MS group was 0.59 years and 1.2 years in the MA group $(p=0.06)$. Conclusions: Minimal access surgical approaches for CPB and 
DHCA during the resection of RCC with extensive tumor thrombus provide similar oncologic control with decreased duration of mechanical ventilation, length of stay and infection related complications. Our findings suggest that MA techniques provide significant advantages over MS.

\section{Keywords}

Renal Cell Cancer, Kidney Cancer, Inferior Vena Cava, Caval Thrombus

\section{Introduction}

A unique feature of Renal Cell Carcinoma is its predilection to involve venous structures. Tumor can grow intraluminally along the renal vein and propagate into the Inferior Vena Cava up to and beyond the right atrium. This occurs in $4 \%-10 \%$ of cases of RCC [1]. If tumor has not spread to lymph nodes or otherwise metastasized, these cancers can be controlled surgically, using a variety of approaches.

Various surgical techniques exist for management of locally advanced RCC with IVC involvement [2] [3]. When tumor thrombus extends above the level of the diaphragm, cardiopulmonary bypass with deep hypothermic circulatory arrest may be utilized to provide maximal exposure to the supradiaphragmatic cava and right atrium and allow for tumor resection in a bloodless field. Two approaches have been developed to accomplish this: median sternotomy (Figure 1 and Figure 2) and a minimal access technique (Figure 3), as we have previously described [4]. The objective of this current study is to review our current experience with both techniques, and compare perioperative complications, perioperative mortality, and recurrence-free and overall survival.

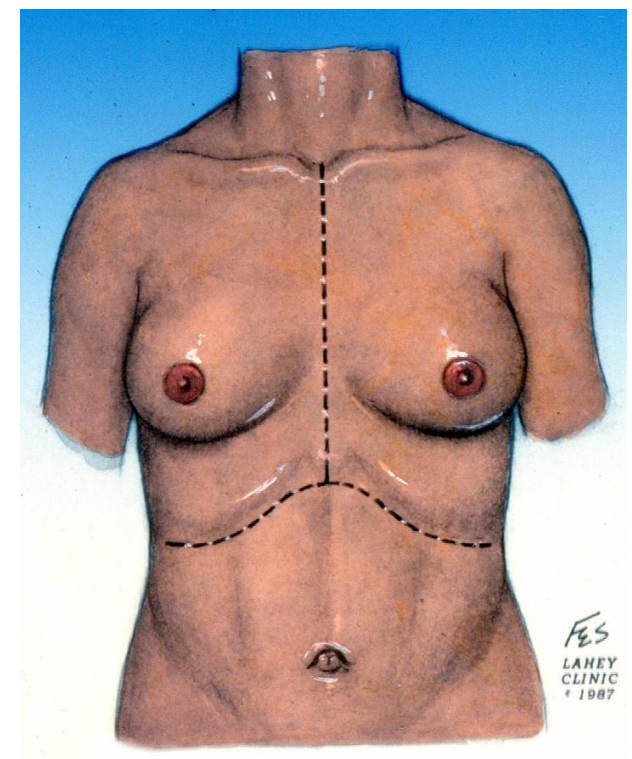

Figure 1. Chevron incision used for traditional median sternotomy approach to CPB. 


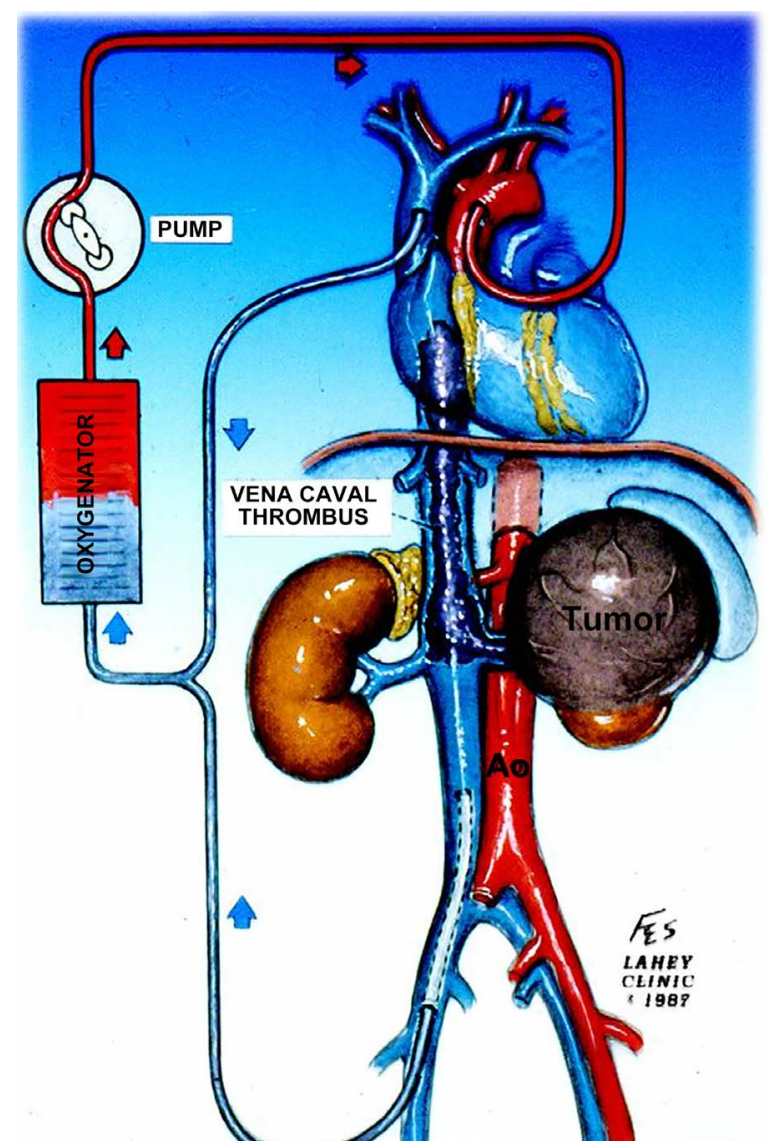

Figure 2. Canulae placement for $\mathrm{CPB}$ using traditional median sternotomy approach.

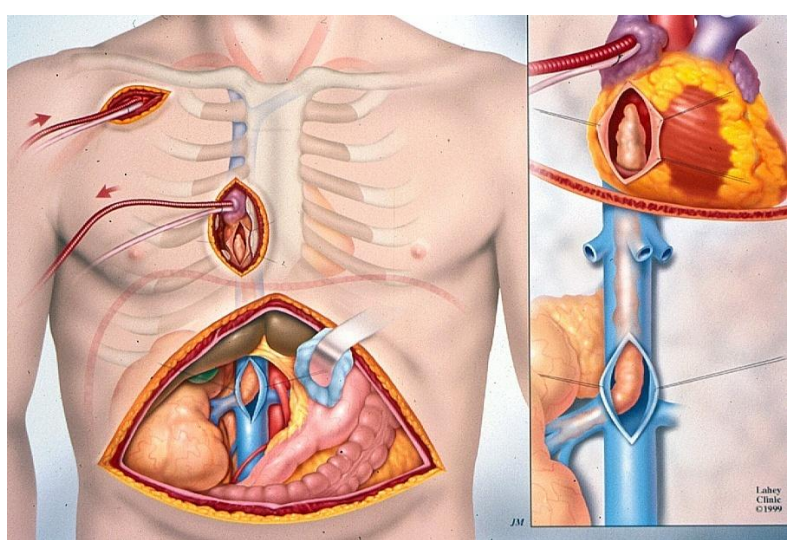

Figure 3. Minimal access technique for $\mathrm{CPB}$.

\section{Materials and Methods}

Between 1986 and 2012, 70 radical nephrectomies and IVC thrombectomies were performed at our institution for patients with renal cell carcinoma with either level 3 or level 4 venous thrombus involvement according to the Neves Classification [5]. We received IRB approval to review the records of these patients. All of these resections were 
performed using cardiopulmonary bypass and deep hypothermic circulatory arrest as per institutional and surgeon preference.

23 patients underwent median sternotomy for the establishment of $\mathrm{CPB}$ and for access to the right atrium and suprahepatic IVC. A chevron incision is performed for access to the infrahepatic vena cava and kidneys. A midline sternal incision is then performed by the cardiothoracic team for access to the mediastinum. The liver is simultaneously mobilized medially using the Langenbach maneuver to expose the retrohepatic cava. Following systemic anticoagulation with heparin an arterial cannula is placed in the upper ascending aorta. A two stage venous cannula is placed via the right atrial appendage and directed into the superior vena cava (SVC) to avoid tumor thrombus in the lower right atrium and IVC. Cardiopulmonary bypass is instituted and the patient systemically cooled to 17 to 18 degrees centigrade. As systemic cooling progresses the patient's head is packed in ice and Solumedrol is administered just prior to DHCA. Circulatory arrest is commenced and the patient is partially exsanguinated into the cardiotomy reservoir for a complete bloodless field.

43 patients underwent $\mathrm{CPB}$ using a modification of a minimal access technique as originally described for aortic valve replacement [6] [7], which utilizes right axillary arterial cannulation and a small right parasternal incision. A right parasternal incision, 2 inches in length, is made over the 4 th rib. The fourth costal cartilage is resected and the pericardium is opened and marsupialized to the wound edge. A two stage venous cannula is placed into the right atrial appendage and directed superiorly into the SVC, as with the MS approach. The right parasternal incision is centered over the right atrium and limits access to the ascending aorta. Consequently, arterial access for CPB is established via the right subclavian artery, which is exposed through a small right infraclavicular incision. The conduct of $\mathrm{CPB}$ is similar to the MS approach. It is important to note that the aorta is not cross-clamped in the MA technique and significant aortic insufficiency is a contra-indication because of the potential for ventricular distension. All patients are screened by echocardiogram preoperatively for the presence of aortic insufficiency. As with the MS technique, following commencement of DHCA, the right atrium is opened while an incision in the IVC is made from within the abdomen. The tumor thrombus is removed from both directions. The right atrium is closed simultaneously with the IVC and the two-stage venous cannula is now re-directed normally into the IVC (Figure 3). CPB is resumed and the patient rewarmed to normothermia. At approximately 30 to 32 degrees centigrade, the heart is defibrillated to a regular rhythm if it has not already spontaneously done so.

Preoperative patient characteristics, pathologic data, and organ specific perioperative complications were analyzed for each group. Where appropriate, continuous and categorical variables were compared using Student's T-test and Chi-squared test. Non-parametric data where analyzed using Kruskal-Walis test. Estimates of overall and disease specific survival were calculated using Kaplan-Meier curves and log-rank testing was utilized to compare survival differences between the TMS and MA groups. In all cases, a p-value of $<0.05$ was considered statistically significant. 


\section{Results}

A total of 70 patients underwent radical nephrectomy with IVC thrombectomy using CPB and DHCA at our institution between 1986 and 2012. Twenty-three patients had a median sternotomy approach and 47 patients underwent a minimal access technique. The majority of MS cases were performed early in the series, as the minimal access technique was developed in the mid 1990s.

The two patient groups showed evenly matched preoperative characteristics and co-morbid conditions (Table 1). From a tumor staging perspective, sternotomy patients were more likely to have higher stage tumors $(86.4 \%$ v. $48.9 \% \geq$ pT3b tumors) and higher rates of nodal metastasis $(21.7 \%$ v. $14.9 \% \geq \mathrm{pN} 1)$. However, a greater number of patients did not undergo LN dissection in the MA group (8.7\% v. 38.3\%), which likely reflects the decreased use of LN dissection over time in general for patients without palpable or radiographic evidence of LN metastasis. Tumor Size and grade were found to be equivalent between groups (Table 2).

Duration of DHCA and CPB were similar between groups. However patients in the MS group required more blood transfusions, had longer operative times, longer mean hospital stays, and longer duration of mechanical ventilation. Patients in the MS group were more likely to require mechanical ventilation $>10$ days, $(47.8 \%$ v. $21.3 \%, p=0.02)$, have higher rates of acute renal failure (30.4\% v. 10.9\%) and prolonged inotropic support $(47.8 \%$ v. $8.9 \%)$ (Table 3 ). Perioperative mortality was also different between groups. Seven MS patients died during their postoperative hospital stay compared to four patients in the MA group (30.4\% v. 8.6\%) (Table 4).

Kaplan Meier curve analysis revealed a significantly improved overall survival and recurrence free survival between groups (Figure 4 and Figure 5).

Table 1. Comparison of baseline characteristics between minimally invasive and median sternotomy groups (p-values are from student t-tests, Kruskal Wallis test, Fisher exact test or chisquare tests where appropriate).

\begin{tabular}{cccc}
\hline & Sternotomy $(\mathrm{n}=23)$ & Minimally Invasive $(\mathrm{n}=47)$ & p-value \\
\hline Age & $63.8+/-10.2$ & $62.8+/-10.3$ & 0.7078 \\
Gender (Male\%) & $52.2 \%(12 / 23)$ & $63.8 \%(30 / 47)$ & 0.3498 \\
Smoking history & & & 0.9443 \\
Never & $31.8 \%(7)$ & $27.9 \%(12)$ & \\
Previous & $40.9 \%(9)$ & $44.2 \%(19)$ & \\
Current & $27.3 \%(6)$ & $27.9 \%(12)$ & 0.6684 \\
Hypertension & $50.0 \%(11 / 22)$ & $55.6 \%(25 / 45)$ & 0.5225 \\
Coronary artery disease & $31.8 \%(7 / 22)$ & $24.4 \%(11 / 45)$ & 0.2429 \\
Pulmonary disease & $9.1 \%(2 / 22)$ & $20.5 \%(9 / 44)$ & 0.2100 \\
Coagulative disorder & $0.0 \%(0 / 22)$ & $6.8 \%(3 / 44)$ & 0.8498 \\
\hline Diabetes & $31.8 \%(7 / 22)$ & $29.5 \%(13 / 44)$ & \\
\hline
\end{tabular}


Table 2. Comparison of tumor characteristics by group.

\begin{tabular}{|c|c|c|c|}
\hline & Sternotomy $(\mathrm{n}=23)$ & Minimally Invasive $(\mathrm{n}=47)$ & p-value \\
\hline \multicolumn{4}{|l|}{ Histology } \\
\hline Clear Cell & $12(54 \%)$ & $34(73 \%)$ & \\
\hline Chromophobe & $0(0 \%)$ & $1(2.2 \%)$ & \\
\hline Papillary & $2(9.1 \%)$ & $2(4.3 \%)$ & \\
\hline Granular & $1(4.5 \%)$ & $2(4.3 \%)$ & \\
\hline Unknown & $7(31.8 \%)$ & $4(8.7 \%)$ & \\
\hline Other & $0(0 \%)$ & $3(6.5 \%)$ & \\
\hline Path Stage $\mathrm{T}$ & & & 0.0004 \\
\hline $\mathrm{T} 3 \mathrm{~b}$ & $2(9.1 \%)$ & $23(51.1 \%)$ & \\
\hline $\mathrm{T} 3 \mathrm{c}$ & $19(86.4 \%)$ & $22(48.9 \%)$ & \\
\hline $\mathrm{T} 4$ & $1(4.5 \%)$ & $0(0 \%)$ & \\
\hline Path Stage N & & & 0.0453 \\
\hline No & $16(69.6 \%)$ & $22(46.8 \%)$ & \\
\hline $\mathrm{N} 1$ & $3(13.0 \%)$ & $3(6.4 \%)$ & \\
\hline $\mathrm{N} 2$ & $2(8.7 \%)$ & $4(8.5 \%)$ & \\
\hline NX & $2(8.7 \%)$ & $18(38.3 \%)$ & \\
\hline Tumor Grade & & & 0.5067 \\
\hline 1 & $0(0 \%)$ & $2(4.4 \%)$ & \\
\hline 2 & $4(33.3 \%)$ & $9(20.0 \%)$ & \\
\hline 3 & $7(58.3 \%)$ & $22(48.9 \%)$ & \\
\hline 4 & $1(8.3 \%)$ & $12(26.7 \%)$ & \\
\hline Tumor Size (cm) & $8.25(6.5-11)$ & $8.75(6-12)$ & 0.6655 \\
\hline
\end{tabular}

Table 3. Comparison of postoperative complications by group.

\begin{tabular}{cccc}
\hline & Sternotomy $(\mathrm{n}=23)$ & Minimally Invasive $(\mathrm{n}=47)$ & $\mathrm{p}$-value \\
\hline Vent $>10$ days & $11(47.8 \%)$ & $10(21.3 \%)$ & 0.0228 \\
Tracheostomy & $6(26.1 \%)$ & $5(10.9 \%)$ & 0.0953 \\
Pleural Effusion & $4(17.4 \%)$ & $5(10.9 \%)$ & 0.4697 \\
Prolonged inotrope use & $11(47.8 \%)$ & $4(8.9 \%)$ & 0.0002 \\
Arrhythmias & $4(17.4 \%)$ & $13(28.9 \%)$ & 0.3002 \\
Acute Renal Failure & $7(30.4 \%)$ & $5(10.9 \%)$ & 0.0433 \\
Sepsis & $8(34.8 \%)$ & $8(17.4 \%)$ & 0.1066 \\
Wound Infection & $4(18.2 \%)$ & $0(0.0 \%)$ & 0.0029 \\
Pneumonia & $3(13.6 \%)$ & $5(10.9 \%)$ & 0.7647 \\
Cholecystitis & $1(4.5 \%)$ & $1(2.2 \%)$ & 0.5882 \\
Coagulopathy & $6(26.1 \%)$ & $4(8.9 \%)$ & 0.0582 \\
Ascites & $3(13.0 \%)$ & $1(2.2 \%)$ & 0.0728 \\
Janundice & $2(8.7 \%)$ & $2(4.4 \%)$ & 0.4809 \\
\hline
\end{tabular}


Table 4. Comparison of surgical outcomes by group.

\begin{tabular}{cccc}
\hline & Sternotomy $(\mathrm{n}=23)$ & Minimally Invasive $(\mathrm{n}=47)$ & p-value \\
\hline Surgical Time (min) & $600(493-753)$ & $476(420-542)$ & 0.0083 \\
Deep Hypothermic Cardiac & $33(19-53)$ & $30(22-38)$ & 0.6202 \\
Arrest (DHCA) Time (min) & & & \\
Cardiopulmonary Bypass (CPB) & $133(102-170)$ & $147(133-163)$ & 0.3263 \\
Time (min) & $11(9-28)$ & $7.5(4.5-14)$ & 0.0473 \\
Blood Transfusions & $26(10-114)$ & $12(9-18)$ & 0.0038 \\
Length of Hospital Stay (days) & $7(3-110)$ & $4(2-7)$ & 0.0102 \\
Intubation Time (days) & $2(8.7 \%)$ & $13(27.7 \%)$ & 0.0693 \\
Adjuvant Therapy & $2(100 \%)$ & $3(23.1 \%)$ & \\
XRT & $0(0 \%)$ & $9(69.2 \%)$ & \\
Systemic Therapy & $0(0 \%)$ & $1(7.7 \%)$ & 0.0179 \\
Systemic Therapy + XRT & $7(30.4 \%)$ & $4(8.5 \%)$ & 0.0152 \\
Perioperative Mortality & $91.3 \%(21 / 23)$ & $43.8 \%(30 / 47)$ & 0.8412 \\
Overall Mortality & $40.9 \%(9 / 22)$ & $(20 / 46)$ & \\
Recurrence & &
\end{tabular}

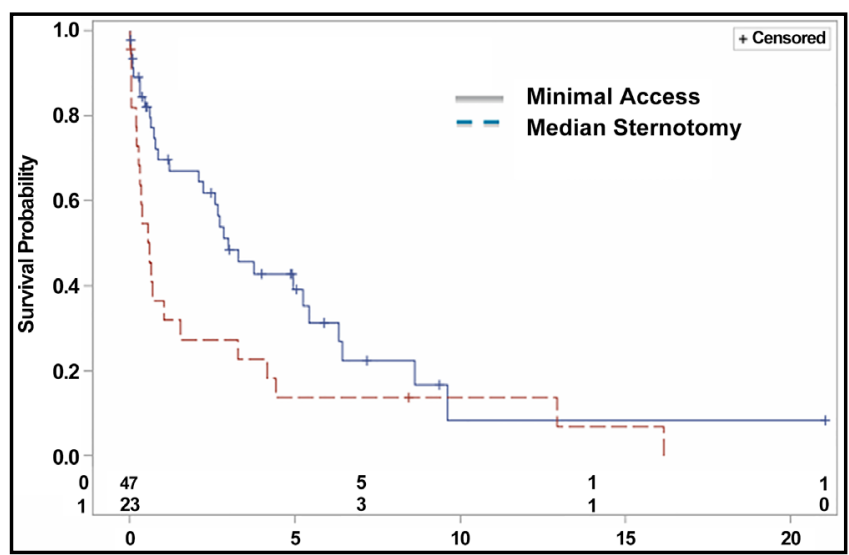

Figure 4. Overall survival comparing minimal access technique to median sternotomy.

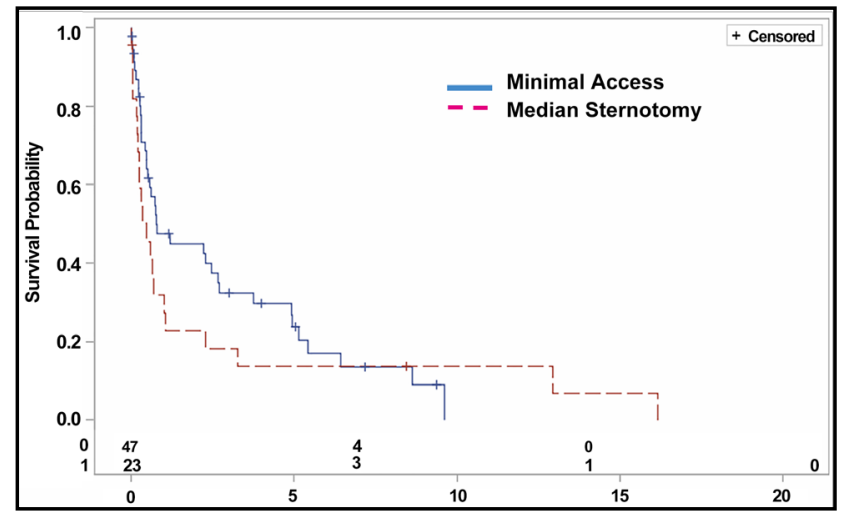

Figure 5. Recurrence free survival comparing minimal access technique to median sternotomy. 


\section{Discussion}

Various techniques for the removal of in tracaval tumors have been described and the technique has evolved over time [8] [9]. Although some investigators have removed Neves level 4 tumor thrombii without the aid of cardiopulmonary bypass, our experience has been that CPB allows for better overall exposure and control of supradiaphragmatic caval and atrial thrombii and allows for caval reconstruction as needed for caval wall invasion utilizing pericardium.

Originally described by Cosgrove [6] for aortic valve surgery and modified for use in $\mathrm{CPB}$ renal surgery, the minimal access right parasternal approach to the right atrium and suprahepatic vena cava has become a very useful addition to the urologic on cologists' armamentarium for radical vena caval surgery [10]. It provides excellent exposure to all portions of the IVC; caval wall resection and/or reconstruction become necessary. Additionally, reduced thoracic trauma resulting from the smaller incision and absence of sternotomy facilitates pulmonary recovery, earlier extubation and shorter hospital stay, and reduces wound complications.

As shown in our analysis, a statistically and clinically significant difference was observed between groups in terms of perioperative in-hospital mortality. We believe that these findings reflect the impact of decreased perioperative complications such as prolonged mechanical ventilation, decreased blood loss, and shorter ICU and hospitalization times.

One potential confounding variable is the chronologic nature of our series. The majority of median sternotomy patients were operated on in our early experience with radical vena caval surgery, whereas the MA patients were treated in our more recent experience within the last twenty years. Newer advances in critical care medicine, refinements in surgical technique, and overall improvements in medicine may have been contributors to the survival benefit in the MA group.

Another potential variable is the advent of targeted therapy during the MA era. As shown in Table 4, the only adjuvant therapy available to patients treated early in our series was adjuvant radiotherapy, which may be of limited benefit in RCC [11]. Systemic targeted therapy in the form of Tyrosine Kinase Inhibitors, mTOR inhibitors, and immunotherapy became available to later patients. Greater than one quarter of all patients who underwent a MA IVC Thrombectomy received some form of systemic therapy. This may have impacted their recurrence-free and overall survival, as TKIs have shown to do in advanced mRCC [12] [13].

We acknowledge the limitations of our retrospective research design. However, in light of the treatment challenges posed by advanced RCC and the extensive nature of the surgical procedure, a prospective randomized trial would be exceedingly difficult to perform. We believe that this study provides evidence to support the use of a minimal access technique for the resection of advanced renal cell carcinoma with cavo-atrial extension and that the technique provides significant advantages with regard to postoperative recovery which may ultimately impact survival. 


\section{Acknowledgements}

We would like to acknowledge Robin Ruthazer for providing assistance with the statistical analysis of the paper.

\section{References}

[1] Hatcher, P.A., Anderson, E.E., Paulson, D.F., Carson, C.C. and Robertson, J.E. (1991) Surgical Management and Prognosis of Renal Cell Carcinoma Invading the Vena Cava. Journal of Urology, 145, 20-23.

[2] Taweemoknongsap, T., et al. (2008) Surgical Treatment of Renal Cell Carcinoma with Inferior Vena Cava Thrombus: Using Liver Mobilization Technique to Avoid Cardiopulmonary Bypass. Asian Journal of Surgery, 31, 75-82. http://dx.doi.org/10.1016/S1015-9584(08)60062-7

[3] Parekh, D.J., Cookson, M.S., Chapman, W., Harrell Jr., F., Wells, N., Chang, S.S., et al. (2005) Renal Cell Carcinoma with Renal Vein and Inferior Vena Caval Involvement: Clinicopathological Features, Surgical Techniques and Outcomes. Journal of Urology, 173, 1897 1902. http://dx.doi.org/10.1097/01.ju.0000158459.42658.95

[4] Wotkowicz, C., et al. (2006) Management of Renal Cell Carcinoma with Vena Cava and Atrial Thrombus: Minimal Access vs Median Sternotomy with Circulatory Arrest. BJU International, 98, 289-297. http://dx.doi.org/10.1111/j.1464-410X.2006.06272.x

[5] Neves, R.J. and Zincke, H. (1987) Surgical Treatment of Renal Cancer with Vena Cava Extension. British Journal of Urology, 59, 390-395. http://dx.doi.org/10.1111/j.1464-410X.1987.tb04832.x

[6] Cosgrove, D.M. and Sabik, J.F. (1996) Minimally Invasive Approach for Aortic Valve Operations. The Annals of Thoracic Surgery, 62, 596-597. http://dx.doi.org/10.1016/0003-4975(96)00418-3

[7] Svensson, L.G. and D’Agostino, R.S. (1998) “J” Incision Minimal-Access Valve Operations. The Annals of Thoracic Surgery, 66, 1110-1112. http://dx.doi.org/10.1016/S0003-4975(98)00655-9

[8] Ciancio, G., Shirodkar, S.P., Soloway, M.S. and Salerno, T.A. (2009) Techniques for Avoidance of Sternotomy and Cardiopulmonary Bypass during Resection of Extensive Renal Cell Carcinoma with Vena Caval Tumor Thrombus Extension above the Diaphragm. Journal of Cardiac Surgery, 24, 657-660. http://dx.doi.org/10.1111/j.1540-8191.2009.00880.x

[9] Ciancio, G., Shirodkar, S.P., Soloway, M.S., Livingstone, A.S., Barron, M. and Salerno, T.A. (2010) Renal Carcinoma with Supradiaphragmatic Tumor Thrombus: Avoiding Sternotomy and Cardiopulmonary Bypass. The Annals of Thoracic Surgery, 89, 505-510. http://dx.doi.org/10.1016/j.athoracsur.2009.11.025

[10] Fitzgerald, J.M., Tripathy, U., Svensson, L.G. and Libertino, J.A. (1998) Radical Nephrectomy with Vena Cavalthrombectomy Using Minimal Access Approach for Cardiopulmonary Bypass. Journal of Urology, 59, 1292-1293.

http://dx.doi.org/10.1016/S0022-5347(01)63584-5

[11] Gez, E., Libes, M., Bar-Deroma, R., et al. (2002) Postoperative Irradiation in Localized Renal Cell Carcinoma: The Rambam Medical Center Experience. Tumori Journal, 88, 500-502.

[12] Cost, N.G., Delacroix Jr., S.E., Sleeper, J.P., et al. (2011) The Impact of Targeted Molecular Therapies on the Level of Renal Cell Carcinoma Vena Caval Tumor Thrombus. European Urology, 59, 912-918. http://dx.doi.org/10.1016/j.eururo.2011.02.032 
[13] Kown, T., Lee, J.L., Kim, J.K., et al. (2014) The Choi Response Criteria for Inferior Vena Cava Tumor Thrombus in Renal Cell Carcinoma Treated with Targeted Therapy. Journal of Cancer Research and Clinical Oncology, 140, 1751-1758.

http://dx.doi.org/10.1007/s00432-014-1703-6

Submit or recommend next manuscript to SCIRP and we will provide best service for you:

Accepting pre-submission inquiries through Email, Facebook, LinkedIn, Twitter, etc.

A wide selection of journals (inclusive of 9 subjects, more than 200 journals)

Providing 24-hour high-quality service

User-friendly online submission system

Fair and swift peer-review system

Efficient typesetting and proofreading procedure

Display of the result of downloads and visits, as well as the number of cited articles

Maximum dissemination of your research work

Submit your manuscript at: http://papersubmission.scirp.org/

Orcontact jct@scirp.org 